\section{A história do rádio catarinense pela voz de seus pioneiros}

\section{Silnei Scharten SOARES ${ }^{1}$}

MUSTAFÁ, Izani. Alô, Alô, Joinville! Está no ar a Rádio Difusora! A radiodifusão em Joinville/SC (1941-1961). Joinville: Casamarca, 2009.

O livro da jornalista e professora Izani Mustafá é resultado de sua dissertação de mestrado defendida no Programa de Pós-graduação em História da UDESC (Universidade do Estado de Santa Catarina), em 2009. Nele, a autora narra a implantação do rádio em Joinville, SC, detendo-se nas três primeiras emissoras que se instalaram na cidade, a Rádio Difusora AM, em 1941, e as rádios Colon, em1958, e Cultura, em 1959.

Com o objetivo de "estudar a radiodifusão em Joinville para conhecer e compreender as motivações pessoais, políticas, sociais e culturais que contribuíram para que as três primeiras emissoras funcionassem", Mustafá recorre a uma metodologia que combina pesquisa em fontes primárias com história oral, que se complementam na tarefa de reconstituir o período de 20 anos - entre 1941 e 1961 - em que as rádios foram implantadas. É neste recorte temporal que são inventariados os passos dos pioneiros do rádio joinvilense em busca da concretização de suas ambições; também nestes vinte anos identificam-se as alianças políticas e empresariais que permitiram tornar realidade os sonhos destes precursores.

Dividido em duas partes, às quais correspondem as metodologias citadas - pesquisa documental na primeira parte, coleta de depoimentos na segunda -, o livro de Mustafá reconstrói as origens da radiodifusão em Joinville procurando articular eventos locais e regionais à política nacional, enfatizando ações como a Cam-

1 Graduado em Comunicação Social pela UFSM, especialista em Produção Cinematógráfica pela PUC-RS, mestre em Comunicação e Informação pela UFRGS e doutorando em Comunicação pela UnB. Atualmente, pesquisa as relações entre a semiótica de Charles Sanders Peirce a as teorias da comunicação. panha de Nacionalização, que proibia o uso de línguas estrangeiras no território brasileiro, e a criação do DIP (Departamento de Imprensa e Propaganda), que regulava a atividade da imprensa, ambas no primeiro governo Vargas, durante o Estado Novo.

É exatamente neste contexto de repressão política e cultural que Wolfgang Brosig, neto de alemães, inicia suas experiências com radiodifusão em Joinville, em meados dos anos 40 do século passado. Movido antes pela curiosidade que pela ambição, e atuando inicialmente mais como inventor do que como empreendedor, Brosig desenvolve um aparelho capaz de receber transmissões radiofônicas da capital do país. Em 7 de setembro de 1938, por meio de um sistema de alto-falantes instalado no centro da cidade, Brosig retransmite o discurso que Getúlio Vargas fazia por ocasião da data, feito que lhe angariou a simpatia do DIP.

Em 1940, Brosig, que era técnico do Serviço de Alto-falantes, e ainda consertava e vendia aparelhos de rádio, monta uma sociedade com empresários da cidade, de modo a obter verba para compra de equipamentos e solicitar a licença para o funcionamento da emissora. A sociedade tem como diretor superintendente Augusto Montenegro Oliveira, um "brasileiro", ou seja, sem ascendência germânica, o que era uma garantia de obtenção da autorização oficial para o funcionamento da rádio. Além disso, as transmissões, efetuadas em caráter experimental, antes mesmo da concessão da licença, eram todas em português, atendendo à política de nacionalização do governo. É por meio de tais artimanhas que um descendente de alemães, durante o Estado Novo, em plena Campanha de Nacionalização, e sob forte vigilância do DIP, obtém uma licença de radiodifusão; e, assim, a Rádio Difusora inicia suas transmissões oficiais em Joinville em $1^{\circ}$ de fevereiro de 1941.

Entretanto, realmente decisivas para a concessão da autorização foram as relações políticas que os sócios da rádio mantinham com membros do governo local e estadual. De acordo com a autora, "intermediação política para os empresários obterem licenças para o funcionamento de emissoras era comum nessa época”. A esposa de Brosig, Juracy, mantinha relações de amizade com a família Ramos, de onde sairia uma linhagem de políticos importantes - entre eles, Nereu Ramos, governador e, após o Estado Novo, interventor de Santa Cata- 
rina. Posteriormente, em 1946, seria eleito senador pelo PSD.

Em 1945, com a deposição de Vargas, as forças políticas do país se agrupam, prioritariamente, em torno de dois partidos, o PSD (Partido Social Democrático), getulista, e a UDN (União Democrática Nacional), de oposição. O PTB era a terceira maior agremiação e, apesar do apoio a Getúlio, fazia freqüentes alianças com a oposição. A Rádio Difusora, segundo depoimentos colhidos pela autora, era “o quartel general do PSD”, e estava sempre com os microfones abertos a seus partidários e simpatizantes - entre eles, Helmuth Falgater, que viria a ser prefeito de Joinville, e Pedro Ivo Campos, que se tornaria governador do estado.

Foi por meio dessas alianças que outro personagem importante desta história lançou-se à política: Jota Gonçalves, o primeiro locutor a ser contratado pela Rádio Difusora. Segundo depoimentos, conquistou o cargo graças à sua aparência (era "bem apessoado") e à dicção impecável do português, sem carregar nos erres, como era comum entre os descendentes de alemães. Jota soube usar a rádio como veículo para construir sua carreira política, elegendo-se vereador e, depois, deputado estadual pelo PSD.

Jota Gonçalves foi também o fundador da terceira rádio a entrar em funcionamento na cidade, a Rádio Cultura AM, em $1^{\circ}$ de julho de 1959 - embora operasse em caráter experimental desde 1956, com equipamentos doados por Brosig. Segundo depoimentos colhidos por Mustafá, Gonçalves não tinha dinheiro suficiente para montar uma rádio em condições de operar profissionalmente, e teve que aguardar três anos para oficializar a emissora. Nesse ínterim, partidários da UDN, liderados por Pedro Colin, filho do ex-prefeito de Joinville, João Colin, montam a segunda rádio da cidade, a Colon AM, inaugurada em 28 de maio de 1958. Com mais recursos financeiros, e apoio do governo do estado, que, na época, estava nas mãos do PRP (Partido da Representação Popular), coligado à UDN, o grupo udenista finalmente conquista "um veículo de comunicação para divulgar a sua ideologia partidária e ampliar os vínculos na cidade para combater seu principal adversário, o PSD”. O objetivo imediato era enfrentar a candidatura de Jota Gonçalves à prefeitura da cidade. A polarização político-partidária do estado - de um lado, o PSD, da família Ramos; de outro, a UDN de Adolfo Konder e Irineu Bornhausen
- se faz ouvir, em alto e bom som, nos processos de concessão para operação de radiodifusão em Joinville.

É por meio de relatos como os que resumi acima que Mustafá faz ressoar as vozes dos protagonistas desta história: aliando depoimentos a documentos, nos são reveladas as alianças políticas e empresariais que viabilizaram a implantação do rádio em Joinville. O estudo de caso demonstra, assim, toda sua potencialidade ao permitir vincular micro e macro, local, regional e nacional, de forma a desvelar as relações de poder que, desde sempre, permeiam a concessão de serviços de telecomunicação no país.

A pesquisa de Mustafá destaca também o papel desempenhado pelas mulheres nessa etapa de implantação do rádio em Joinville, descrevendo as funções que lhes eram destinadas nas emissoras (muitas, além de locutoras, eram também atrizes, roteiristas e secretárias) e o gênero de programa que lhes cabia apresentar - normalmente, dicas de beleza, culinária, cuidados com a casa e os filhos, além de normas de comportamento em sociedade, contribuindo para a criação de um padrão ideal de feminilidade para a época.

$\mathrm{Na}$ apreciação a que submete a programação das três primeiras rádios da cidade, a autora evidencia a prática de cópia da grade das grandes emissoras do centro do país, principalmente a Rádio Nacional, do Rio de Janeiro: "Programas de auditório ao vivo, de humor, radionovelas, transmissões esportivas e noticiários são alguns gêneros reproduzidos pela Rádio Difusora AM, Colon AM e Cultura AM em Joinville". Outro gênero de programa usual na época era o que atendia os pedidos feitos pelo ouvintes, que se dirigiam até a emissora e pagavam pela execução das músicas, dedicadas a pessoas queridas.

Em meio às semelhanças, cada rádio buscava distinguir-se das outras, muito mais pelo estilo pessoal de seus locutores do que pela programação propriamente dita. A Difusora era mais popular, enquanto a Colon, mais elitizada, montou uma equipe com profissionais mais qualificados. Quando decide montar sua própria emissora, Jota Gonçalves decide inovar, e contrata um profissional com a missão primordial de elaborar uma programação própria, capaz de diferenciar-se das outras duas emissoras, e de contratar a equipe de radialistas; este profissional, Ramiro Gregório, é um dos personagens mais interessantes da narrativa de Mustafá, e é no contraste entre sua história - ou melhor, na forma como ela 
é narrada - e a dos demais, que se evidenciam os méritos e os limites do trabalho da autora.

O envolvimento de Ramiro Gregório com rádio começou em 1953, quando, com 17 anos, é contratado como locutor na Rádio Jaraguá, cidade próxima a Joinville. Dali, muda-se para Indaial, convidado para trabalhar na Rádio Clube local. É nesta emissora que aprende a parte técnica do ofício, trabalhando nas horas vagas na montagem de equipamentos, como mesa de som e transmissor. "Aprendizados técnicos que sempre usou ao longo de sua carreira no rádio", segundo a autora.

Inquieto - "eu era uma espécie de ave de arribação", diz, referindo-se a si mesmo -, logo transfere-se para a Rádio Clube de Brusque, de onde Jota Gonçalves the traz para Joinville, com o convite para montar os equipamentos e definir a programação da emissora que iria inaugurar em Joinville, a Rádio Cultura AM. Ramiro aceita a difícil missão de organizar uma rádio com perfil diferenciado, posicionando-se entre o estilo popular da Difusora e a programação elitizada da Colon.

Na Cultura, Ramiro fez de tudo: da instalação dos equipamentos à contratação e treinamento dos novos locutores - o mais importante, porém foi a definição da programação da rádio. Ciente da necessidade de distinguir-se das concorrentes, Ramiro investe na transmissão esportiva, no noticiário e nas transmissões ao vivo como armas para conquistar a audiência - em depoimento à autora, Ramiro vangloria-se do fato da Rádio Cultura ter sido "a primeira de Joinville a buscar matérias longe do estúdio, em outras cidades, com o repórter levando um gravador para que as entrevistas com as autoridades, visitando outros municípios, pudessem ir ao ar. O diferencial da Cultura era ir onde o fato estivesse acontecendo".

Ramiro introduz também outra novidade: abre os microfones para que, na Rádio Cultura, manifestemse partidários e simpatizantes tanto do PSD quanto da UDN, inviabilizando, desta forma, a subordinação da emissora aos interesses de um ou outro partido. "A rádio tem que ser democrática”, diz Ramiro. Ele permanece na Cultura até 1961, afastando-se devido à incompatibilidade com os filhos de Wolfgang Brosig, que não queriam alguém alheio à família na direção da rádio. Ao deixar a rádio, é convidado para trabalhar na Fundição Tupy, uma das maiores indústrias do estado de Santa Catarina, na função de gerente de vendas em São Paulo. Apesar dos sócios da Tupy manterem relações com a UDN, o bom relacionamento de Ramiro com integrantes de ambos os partidos garantiu-lhe a vaga: inicialmente questionado por sua simpatia ao PSD, o fato de acolher também a UDN na Rádio Cultura foi decisivo para sua contratação.

Depois de três anos na capital paulista, Ramiro é chamado de volta a Joinville para assumir novamente a direção da rádio, agora na condição de sócio. Em 1964, Jota Gonçalves decide vender a Rádio Cultura e a oferece à família Schmidt, proprietária da Fundição Tupy. De acordo com a legislação vigente, no entanto, apenas pessoas físicas poderiam ser proprietárias de empresas de radiodifusão. Ramiro Gregório é então indicado pelo próprio Jota para assumir a direção da emissora; para ter capital suficiente para tornar-se sócio acionista, é demitido da Tupy, de forma a poder usar os recursos da rescisão para a compra das ações.

Com recursos disponíveis e apoio político, a Rádio Cultura entra em nova fase: muda de sede, constrói novos estúdios, contrata locutores de São Paulo, reestrutura-se administrativamente e profissionaliza o setor comercial. As mudanças modernizam a emissora, que supera as concorrentes em termos de organização administrativa e tecnologia.

Após implantar a Cultura FM, em 1980, Ramiro afasta-se da emissora em 1982, e vai trabalhar na Rádio Colon até 1985, como produtor de jornalismo. Em 1986, torna-se sócio da Difusora, que já não pertencia mais a Wolfgang Brosig, onde assume o cargo de diretor superintendente, tornando-se, então, o único radialista a ter trabalhado nas três emissoras pioneiras da cidade.

A história de Ramiro Gregório, recontada a nós por Mustafá, é, de todas, a mais objetiva: ao contrário das narrativas das outras fontes, marcada por detalhes pessoais de pouca relevância para a pesquisa, o relato de Ramiro atém-se a seu envolvimento com a implantação do rádio em Joinville, especificamente, e em Santa Catarina, de modo geral. Qual a razão para essa disparidade? Na descrição de como foram suas entrevistas com Ramiro, a autora nos dá uma pista: "[Ramiro Gregório] Preferiu sempre que a pesquisadora formulasse a primeira pergunta e, a partir daí, ele passava a responder mansamente, com uma riqueza de detalhes" (os grifos são meus). O trecho parece indicar que Ramiro, homem de comunicação com vasta experiência, mesmo na posição de entrevistado, assume, ainda que sutilmente, o controle da situação. Que ele tenha optado por um relato mais fac- 
tual, menos saudosista, e que, por conta dessa escolha, a apresentação de seu relato pela autora reproduza tais características, sugere, mais do que a fidelidade à narrativa dos entrevistados, uma ausência de distanciamento entre a pesquisadora e suas fontes. O fato da apresentação dos outros relatos não se pautar pelos mesmos critérios de objetividade do relato de Ramiro - ao contrário, neles o que predomina é a memória afetiva -, dá a entender que a autora tenha mimetizado o frame narrativo utilizado pelos entrevistados ao contar suas histórias.

Por que isso acontece?Arrisco uma hipótese: radialista experiente e boa ouvinte, a autora recolhe, das histórias que lhe contam, aquele traço de "interesse humano" ao qual aludem os jornalistas para justificar o que merece transformar-se em notícia. Entretanto, a adoção deste critério jornalístico não deveria sobrepor-se aos critérios que conduzem uma pesquisa historiográfica mesmo que se trate de trabalhar com a História do Presente, linha a qual a autora, explicitamente, se filia. Mais do que em qualquer outra vertente da história, no caso da História do Presente, em que o distanciamento temporal em relação ao objeto de pesquisa é reduzido, deve-se exigir do historiador uma vigilância ainda maior, que lhe possibilite tomar uma distância teórica e epistemológica do objeto, minimamente suficiente para evitar tornar-se mera caixa de ressonância das fontes - das orais, principalmente. Caso contrário, o risco do mimetismo é grande, e ficamos nós, leitores, na expectativa de que a autora proponha uma interpretação - compreensiva, pelo menos dos eventos narrados que ultrapasse o mero registro, seja das impressões dos depoentes, seja da crônica dos fatos.

Parece haver, na pesquisa de Mustafá, um conflito entre o compromisso da jornalista com a fidelidade aos fatos e aos relatos das fontes, na tentativa de compor um quadro da atualidade para consumo imediato, e o ofício da historiadora, que busca construir um registro do tempo presente que seja, também ele, um documento histórico permanente, que não caia no esquecimento ao fim do dia. Entre a atualidade jornalística e o tempo presente do historiador há algo mais do que uma distância temporal - há também diferença de perspectiva e de compromisso: o do jornalista, com o factual, a novidade e o "interesse humano"; o do historiador, com o exercício de uma análise interpretativa que atribua ao passado - por próximo que esteja - uma relevância que vá além do fato em si; trata-se, para o historiador, de transformar o fato bruto em signo da história pelo exercício do pensamento (afinal, o fato, em história, como em qualquer outra ciência, é uma construção teórica).

Esta contradição, não entanto, não retira os méritos do trabalho, que, por meio de pesquisa minuciosa em arquivos públicos e privados, e pela coleta paciente dos depoimentos, se esmera em resgatar, para futuras gerações de pesquisadores, a história da implantação da radiodifusão em Joinville, repleta de lances de ousadia e inquietação. 